\title{
NOVEDADES BIBLIOGRÁFICAS SOBRE EL CORÁN Y MAHOMA
}

\author{
Por \\ LUIS F. BERNABÉ \\ MÍKEL DE EPALZA
}

En 1979 el doctor Julio Cortés Soroa, arabista bilbaíno y profesor en la Universidad de North Carolina (U.S.A.), ofrecía la primera edición de su excelente traducción del Corán al castellano (1). Ahora hay que celebrar el que esa traducción al castellano haya aparecido dentro de una edición bilingüe, con el texto árabe original, a dos columnas: Julio Cortés, Al-Qur'ān al-Karimm. El Corán. Edición, glosario y traducción, Indice analítico por Jacques Jomier, New York, AKZ Publications, 1987, VII-XXVIII-634 pp; distribución para Europa: Al-Hidaya International, 37 Princess Avenue, Waltford Herts WD1 7RR, United Kingdom.

Es ésta, creemos, una buena ocasión, para presentar una serie de publicaciones recientes sobre el Corán y sobre Muhámmad (transcripción más fiel de Mahoma de acuerdo con el nombre original en árabe), situándonos especialmente en el conjunto de las obras sobre estos temas en las lenguas hispánicas (2).

Como quiera que el árabe es la lengua única e idónea en la que las enseñanzas del Corán pueden ser transmitidas con toda fidelidad, los teólogos musulmanes consideran la traducción como un mero comentario de los significado, conceptos o ideas (máānì), por lo que el sistema del texto bilingüe es

(1) Julio Cortés, El Corán, Madrid, Editora Nacional, con sucesivas ediciones y reimpresiones, hasta la desaparición de esa editorial, pasando la edición, a partir de 1986, a la editorial Herder de Barcelona

(2) Ver ya un precedente de este tipo de estudios en: J. Vernet, "Coránica" Al-Andalus, Madrid, 27, (1962), 449-454; M. de Epalza, "Una nueva traducción castellana del Corán», Almenara, Madrid, 4, (1973), pp. 239-242 
"obligatorio" para las traducciones islámicas del Corán a lenguas no árabes (aljamía). En España, se dieron traducciones parciales y comentarios coránicos en textos manuscritos de mudéjares y moriscos, los últimos musulmanes de la Península, ya sean en caracteres árabes, pero reproduciendo el romance hispano, o en caracteres latinos (3). Estos hispanomusulmanes fueron progresivamente perdiendo el habla de sus mayores ante las condiciones terriblemente adversas en las que iban transcurriendo sus vidas, hasta llegar al punto de que les fue inaccesible el Corán, a no ser por medio de unas traducciones aljamiadas que -posiblemente siguiendo el entonces prestigioso modelo otomano- acercaron el Libro Sagrado musulmán a la única lengua en la que se expresaban (4).

Pero pronto se vio que no era únicamente el árabe en lo que mudéjares y moriscos habian disminuido de forma alarmante sus conocimientos; también en lo referente a todo el universo islámico la situación que se habian visto obligados a sobrellevar había sido muy perjudicial para sus conocimientos, de tal forma que se hicieron imprescindibles unas glosas o comentarios coránicos que fueran interpretando y explicando las enseñanzas de Allah (5). Tales comentarios fueron ampliándose sucesivamente para poder aprehender en su totalidad el complejo corpus religioso islámico y, al mismo tiempo, dotar a los hispanomusulmanes de una visión sólida de su religión que les sirviese como elemento fundamental de afirmación personal frente a la mayoría cristiana: de aquí nacieron las narraciones y poemas en alabanza a Allah, Muhammad y la religión islámica que se perpetuarán -ya definitivamente en el mismo romance que hablaban sus enemigos religiosos- más allá de las fronteras peninsulares, cuando el exilio de esta comunidad fue ya un hecho consumado (6).

Pero a las razones religiosas que exigen tal composición a las versiones no árabes del Corán, hay que añadir para los estudiosos del Islam y de su texto fundamental la comodidad de la edición bilingüe a dos columnas, tal y como se ha realizado en otras lenguas, sea encuadrando en la misma página el texto coránico árabe con la escritura en otra lengua (sistema utilizado por los turcos desde los años veinte, en que cambiaron la escritura árabe por

(3) Ambas producciones son, stricto sensu, aljamias en tanto lengua no árabe, si bien se suele utilizar el término en los últimos tiempos al hablar de una literatura aljamiada para referirse a la escrita en romance pero con caracteres árabes

(4) Vid. Teresa Losada, Estudios sobre Coranes Aljamiados, Tesis Doctoral, Barcelona, 1977; Wilhelmina Al-Ganabi, La Escuela Coránica de Denia: Abū 'Amr 'Utmān b. SacTó Ad-DānI. Figura, obra formativa y obra escrita, Tesis Doctoral, Universidad de Granada, 1988; María José Hermosilla, «Una versión aljamiada del Corán, 58, 1-3», Al-Qanțara, IV, (1983), pp. 423-427

(5) J. Vernet, "Traducciones moriscas de 'El Corán'”, Der Orient in der Forschung. Festschrift für Otto Spies, Wiesbaden, 1967; J. Vernet y L. Moraleda, "Un Alcorán fragmentario en aljamiado", Brablb; 33, (1969. 1970); J. Vernet, "La exégesis musulmana tradicional en los Coranes aljamiados", Actas del Coloquio Internacional sobre Literatura Aljamiada y Morisca. Oviedo, 1972 (Madrid, 1978); C. López Morillas, The Qur'an in sixteenth-century Spain: six morisco versions of sura 79, London, Tamesis Books, 1982

(6) Vid. por ejemplo Toribio Fuente Cornejo, Poesía religiosa aljamiado-morisca, Tesis Doctoral, Universidad de Oviedo, 1985, por lo que se refiere a una primera producción todavía con caracteres árabes; en cuanto a las obras ya plenamente en romance, esencialmente escritas ya en el exilio, vid., Luis $F$. Bernabé, El Cántico islámico del morisco hispanotunecino Taybili, Zaragoza, Institución Fernando el Católico, 1988 
la latina), sea con los dos textos en páginas diferentes enfrentadas, como ha sido hecho recientemente en la versión inglesa por una editorial libanesa de El Cairo y en la magnífica traducción francesa de Denise Masson (revisada por el muftí libanés Subhi Saleh).

Era también esa misma editorial libanesa la que buscaba arabistas españoles para realizar la edición bilingüe al castellano, pero, como se ha señalado, la asociación pakistaní Aza Khana-e-Zahra ha sido la primera en llevarla a término. $Y$ hay que felicitarse de que la traducción usada haya sido la del profesor Julio Cortés, pues une a la fidelidad al texto original una gran corrección del léxico religioso castellano correspondiente a las en absoluto fáciles de traducir nociones religiosas árabes. Otro de sus méritos más eminentes es su sencilla belleza estilística en castellano, exigible para un texto de gran valor estético como es el Corán en árabe. Un solo inconveniente podría otorgársele a esta edición bilingüe: su elevado precio, que pudiera ser quizá abaratado con reimpresiones más asequibles en ediciones españolas.

Pero no solamente la traducción de Cortés conoce repetidas ediciones en España. Otras varias vienen reseñadas en la laboriosa obra realizada y editada por The Research Centre for Islamical History, Art and Cultura, de Istanbul: el catálogo de traducciones a diversas lenguas titulado World Bibliography of Translations of the Meanings of the Holy Quran. Printed Translations 15151980 (7). Con una excelente presentación bibliográfica, recoge 35 ediciones en castellano entre las páginas 415-425, si bien la número 1515/11, editada en Copenhague en 1970, debe estar en esperanto y no en castellano: son las ediciones hechas por Bergua (1931, pero también las del mismo, no identificado al aparecer con sus siglas J.B.B.O., en 1931, 1945 y otras), Cansinos $(1951,1954,1961,1973)$, Cansinos y Abboud (1953, 1974), Hernández Cata (1913, 1936, 1937), Cortés (1979, 1980), García-Bravo (1907, 1972), Murguiondo (1875), Ortiz (1872), Garber de Robles (1844), Rahhal y Peralta $(1945)$, Vernet $(1953,1963,1973,1980)$ y también las traducciones parciales de Borrego (1844), Cardona (1965), Gavaldá (19567 y Machordom (1980).

Al listado de este catálogo cabría añadir, para antes de 1980 -fecha tope que se ha fijado-que la traducción del profesor Juan Vernet de 1963 es nueva con respecto a la de 1953, y que fue reimpresa en 1967, 1973 y 1983 (Editorial Planeta), mientras que la de 1980 sigue la de 1953 (Editorial Plaza y Janés). La traducción, en ediciones económicas, de Bergua del año 1931 estaba por su $10 .^{\text {a }}$ edición en 1978, a partir de su forma definitiva establecida en 1975. La de García-Bravo del año 1907, fue reimpresa en 1972, así como en 1979, 1983 y 1986, ésta última por Ediciones Gaviota de Barcelona, aunque sin mención del nombre del traductor. La traducción de Cortés de 1979, reimpresa en 1980, fue reedictada también por Editora Nacional en 1984.

(7) Edición preparada por Ismet Binark y Halit Eren, con introducción del director del Research Centre Dr. Ekmeleddin lissanoglu, Istanbul, 1406 H/1986JC, 34-880 pp. 
Habría, por tanto, que completar con estos añadidos en castellano la importante obra bibliográfica realizada en Istanbul, puesto que no consta que haya habido traducciones editadas en catalán y gallego, si bien se anunció una en euzkera. Desde el punto de vista sociológico, esta proliferación de ediciones, que son generalmente reimpresiones y además de viejas traducciones a las que los editores no tienen que pagar derechos de autor, indica una importante demanda y una elevada curiosidad por parte del público lector hispánico.

Por otra parte, no es necesario insistir, por obvio y conocido, que no todas estas traducciones tienen el mismo valor: sólo las de Vernet y Cortés se harridecho directamente a partir del árabe. A las que han tenido la revisión de un árabe (Abboud, Rahhal), no cabe suponerles por este hecho una competencia especial; $y$, finalmente, hay introducciones a algunas de esas versiones que contienen afirmaciones particularmente ofensivas contra las creencias musulmanas (Murguiondo, Bergua).

Acerca de publicaciones recientes sobre el Corán, hay que mencionar que el Centro Islámico en España ha editado en fechas recientes la traducción al castellano hecha por Raisuni del ya clásico estudio divulgativo que hiciera el intelectual argelino Malek Bennabi en 1946, en plena ocupación francesa (8). Por su parte, José Antonio Pacheco ha realizado un estudio de carácter filosófico sobre los Libros Revelados que hay que reseñar por su originalidad dentro de la producción hispánica sobre el tema, aunque es necesario señalar que privilegia dentro de su estudio a los libros hebraicos y a las interpretaciones esotéricas del Libro del Islam (9).

Un instrumento de trabajo muy importante para el estudio del Corán acaba de aparecer en España, aunque debido a dos estudiosos canadienses: se trata de Las concordancias del Corán, de Hanna E. Kassis y Karl I. Kobbervig (10). Se trata de un índice del léxico coránico, transcrito en letras latinas, por raíces, explicando el significado de cada término y señalando los versículos del Corán en los que aparece. Hasta ahora, para encontrar una determinada palabra en el Corán había que utilizar libros de concordancias escritos sólo en árabe y con la simple mención léxica. Dos índices complementarios hacia el final de la obra hacen este libro particularmente valioso para las investigaciones islamológicas: el "Vocabulario Asociado con el Nombre Divino" (pp. 683-738) y un undice» final de conceptos hispánicos con sus correspondientes raíces léxicas en árabe, que funciona -en cierta manera-como vocabulario español-árabe para el léxico coránico (pp. 739-882).

(8) Malek Bennabi, El Fenómeno Coránico, Madrid, 1986, $125 \mathrm{pp}$

(9) José Antonio Antón Pacheco, Symbolica Nomina. Introducción a la hermenéutica espiritual del Libro, Barcelona, 1988, $230 \mathrm{pp}$.

(10) Madrid, Instituto Hispano-Árabe de Cultura, 1987, 882 pp. En esta obra se han omitido algunas partículas frecuentísimas, con justificación de tales omisiones en $\mathrm{p}$. XX). Vid. un precedente en árabe de este nuevo libro: Muhammad Fu'Ad 'Abd al-BAqI, Al-Mu'yam al-mufahris li-alfaz al-Qur'an al-karim, El Cairo, 1965 
Pasando de las publicaciones sobre el Corán a las que se centran en Muhámmad, su revelador como Profeta del Islam, hay que recoger al reciente libro de Juan Vernet, que realiza en edición popular una biografía del personaje, utilizando generalmente traducciones directas de textos árabes, del Corán y de biografías medievales (11). Entre tantas biografías en castellano que son traducciones de autores extranjeros, se distingue, pues, esta obra original, como también lo fue, en 1979, la del musulmán español Alvaro Machordom Comins, de estilo menos erudito y más directo y testimonial: Muhammad (57-632) Profeta de Dios (12).

Estas dos biografías en castellano deberían figurar en futuras ampliaciones de otra importante novedad bibliográfica sobre temas relacionados con Mahoma. Se trata de la Guide to Sira and Hadith Literature in Western Languages (13), ampliación y refundición muy mejorada, ordenada temáticamente, del mero catálogo alfabético realizado por los mismos autores, Muhawar Ahmad Anees y Alia Nasreen Athar, en 1980/1400H: Hadith and Sira Literature in Western Languages. A Bibliographic Study (14). Se trata de casi 3.000 títulos (sólo 1.604 en la obra primitiva), especialmente en lengua inglesa, ordenados en capítulos agrupados en cuatro partes: I. Obras de referencia; II. Obras sobre la Dira (o biografía de Muhámmad); III. Obras sobre la Sira y temas afines del Judaísmo y del Cristianismo; IV. Obras sobre el Hadith (o textos referentes a hechos, dichos o permisiones del Profeta). Un índice de autores completa esta obra, particularmente exhaustiva para con trabajos publicados en el mundo indo-pakistaní y anglosajón.

Quizá sea por esta última razón por lo que se explica la parquedad de noticias de este valioso libro acerca de publicaciones sobre Muhámmad en el mundo hispánico: sólo se mencionan algunas de César E. Dubler, Míkel de Epalza, Braulio Justel Calabozo (en «Calabozo»), Félix M. Pareja y María Jesús Viguera. La producción hispánica, sin ser muy abundante, podría abarcar desde la curiosa obra del siglo XVIII de Fray Manuel de Santo Tomás de Aquino, Verdadero carácter de Mahoma y de su religion: justa idea de este falso profeta, sin alabarlo con exceso, ni deprimirle con odio (Valencia, 1793) a María Jesús Rubiera Mata: «Las décimas del Profeta (muªšsarāt, cišrinniyyāt, țalātininiyyāt y mujammasāt: versos con epanadiplosis en la poesía hispano-árabe) (15), sin olvidar los temas muhammádicos en Asín Palacios y otros: También se podría estudiar la bibliografía de los musulmanes de lengua hispánica como el argentino Abbud, el español Machordom, o las publicaciones de diversos grupos afincados en España como los ahmadíes sobre el tema; así como las monografías sobre como vieron al Profeta autores antiguos: los mudéjares y moriscos en la obra de Pedro Longás, La vida religiosa

\footnotetext{
(11) Juan Vernet, Mahoma (Muhammad), Madrid, Espasa-Calpe, 1987, 191 pp.

(12) Madrid, Editorial Fundamentos, 1979

(13) London \& New York, Mansell, 1986, XXX11-371 pp.

(14) Sin lugar expreso de edición, simplemente "Manufactured in the United States of America». En cuanto a la ordenación, contiene nada más que un pequeño índice temático (pp. 432-461)

(15) Al-Qantara, Madrid, 1, (1980), pp. 55-64
} 
de los moriscos (Madrid, 1915), o los cristianos, como el trabajo de M. de Epalza, "Un logos cristià enfront de I'Islam: Eiximenis escrivint sobre Mahoma" (16) o el curioso de Guadalupe Sáiz, "Críticas contra el profeta Muhāmmad en la obra "El obispo de Jaén sobre la seta Mahometana" (17).

Para acabar y como anécdota sobre las dificultades del acceso de la bibliografía hispánica a nivel internacional, en temas de islamología, el artículo de M. de Epalza, «Los nombres del Profeta en la Teología Musulmana» (18). viene recensionada en la monumental obra ya mencionada de Anees y Athar con el siguiente comentario (p. 317): "A study on nomber of prophets according to Muslim Theology". Los "nombres del Profeta" se han transformado en el «número de profetas»...

(16) Homenatge a Joan Fuster, Montserrat (En prensa)

(17) Homenaje al profesor Dario Cabanelas Rodriguez O.F.M., con motivo de su LXX aniversario, Universidad de Granada, 1987, vol. I, pp. 477-490

(18) Miscelánea Comillas, Madrid, 32, (1975), pp. 149-203 